\title{
Rheumatic fever and rheumatic heart disease in Africa
}

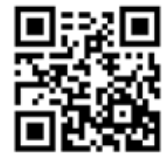

Acute rheumatic fever (ARF), with its varied and potentially devastating cardiac complication of rheumatic heart disease (RHD), has largely been eradicated from developing countries, but continues to be a scourge mainly in poorly resourced areas of the world and also among the indigenous populations of some wealthy countries such as New Zealand and Australia. ${ }^{[1]}$ The disease is particularly prevalent in populations where there is overcrowding and high levels of poverty. Efforts have been made to commit to the elimination of ARF/RHD in South Africa (SA) and the rest of Africa. The Drakensberg Declaration, which initiated and promoted the Awareness, Surveillance, Advocacy and Prevention (ASAP) programme to raise public awareness, establish surveillance programmes, advocate for support and promote prevention, was adopted at the 1st All Africa Workshop on Rheumatic Fever and Rheumatic Heart Disease held in the Drakensberg, SA, in 2005. ${ }^{[2]}$ The ASAP programme has unfortunately not been expanded on a national scale so far. Subsequent attempts at solutions to controlling ARF and RHD globally have included the establishment of registers to track disease outcomes and outline strategies related to the ASAP proposal to improve disease control in low-income countries. ${ }^{[3]}$

Information about levels of $\mathrm{ARF} / \mathrm{RHD}$ is scarce and poorly documented in less-developed areas of the world such as Africa. ${ }^{[4]}$ The prevalence of RHD in SA has been reported occasionally since the landmark study by McClaren et al. ${ }^{[5]}$ in 1975, which showed an overall prevalence rate of RHD (using clinical examination to establish the diagnosis) of $6-9 / 1000$ among schoolchildren in Soweto, Johannesburg. A prospective clinical registry of valvular heart disease using echocardiography to make the diagnosis during 2006/2007 among individuals older than 14 years at Chris Hani Baragwanath Academic Hospital in Soweto revealed an incidence of 23.5/100 000 patients with RHD presenting for the first time. ${ }^{[6]}$ Recent information from the past decade concerning the prevalence of RHD in sub-Saharan Africa has emanated from echocardiography screening studies in asymptomatic schoolchildren. Marijon et al. ${ }^{[7]}$ showed a very high prevalence rate of 30.4/1 000 in Mozambique in 2007. A similarly high prevalence rate of $15 / 1000$ in a much larger cohort of Ugandan schoolchildren was reported in 2012. ${ }^{[8]}$ Two very recent cardiac clinic hospital-based study cohorts from Africa, using echocardiography to confirm diagnoses, showed RHD to be the most important heart condition in patients aged $10-19$ years (affecting $62.1 \%$ ) in Cameroon, ${ }^{[9]}$ while RHD was present in $22.4 \%$ of children undergoing echocardiography at a centre in Malawi. ${ }^{[10]}$

In contrast, a recent publication from $\mathrm{SA}^{[11]}$ has shown a dramatic decline in the number of children younger than 14 years with ARF and RHD presenting to the paediatric cardiology department at Chris Hani Baragwanath Academic Hospital over the 17-year period 1993 2010. The referral population has not changed despite an increase in the number of patients referred to the unit during this period. The population served by this large tertiary care hospital is largely poor and includes the massive periurban population of Soweto, patients referred by secondary hospitals in southern and eastern Gauteng Province, and patients from North West Province. The majority of patients with ARF/RHD were found to have originated from outside Soweto, but the addresses provided could not be validated. Many patients who present with severe disease requiring surgery to repair or replace damaged heart valves are suspected to originate from rural areas, and they include people from beyond SA's borders who have made the informal settlements in and around Gauteng their home. ${ }^{[11]}$
A similar downward trend has been observed at a central hospital complex in Limpopo Province, where a decline in the prevalence of RHD among children up to 13 years old has also been documented. A record review of paediatric echocardiography reports for the period 2001 - 2012 showed that the number of cases decreased from 36 per year for the first 4 years of the study to an average of 14 and six per year in the middle and final 4 years of the study, respectively. During the same time period the number of cases of congenital heart disease diagnosed each year remained relatively constant. This information suggests a decreasing prevalence of childhood RHD in Limpopo Province. ${ }^{[12]}$

Anecdotally, numbers of children presenting to large tertiary hospitals with ARF/RHD have declined in Free State Province, but not in KwaZulu-Natal and rural parts of the Eastern Cape (personal communications, Prof. Stephen Brown, Dr Ebrahim Hoosen and Dr Lungile Pepeta, respectively).

Several sociopolitical changes in SA could have contributed to the documented decline in the numbers of children with ARF/RHD in Gauteng and Limpopo provinces. These include an improvement in the socioeconomic status of the broader population since the new political dispensation in 1994, less overcrowding in dwellings, free healthcare for children under the age of 6 years, more widespread availability of primary healthcare facilities, and easy access to penicillin for the treatment of all sore throats. ${ }^{[12]}$ The latter resulted in a dramatic decline in the incidence of ARF in Costa Rica and Cuba, as has been well documented. ${ }^{[13,14]}$

Information on the incidence and prevalence rates of ARF and RHD in SA and the rest of Africa is needed to ensure targeting of susceptible populations with prevention and treatment programmes. Research opportunities should therefore continue to be created to allow for a pan-African survey of the frequency and origins of patients with ARF/RHD presenting to the larger central and secondary hospitals in SA and other parts of Africa, to assess the need for control strategies in vulnerable areas.

Other methods of detection, such as screening for RHD with echocardiography in schoolchildren, are excellent ways to seek out affected individuals so that secondary prophylaxis can be instituted. Echocardiographic screening is, however, a very costly undertaking requiring expensive equipment, specialised expertise, reliable and relevant diagnostic echocardiographic criteria that can easily be replicated, and time spent by physicians and technical echocardiographic personnel away from their hospital commitments.

The eradication of ARF/RHD is a complex process that needs to be addressed at various levels. These include education of vulnerable communities about the disease, provision of easy access to medical care, and increasing the availability of free penicillin to treat group A streptococcal pharyngitis and for secondary prophylaxis against further attacks of ARF in patients with established RHD. Just as important is to address poverty and overcrowding, which are associated with high levels of ARF and RHD, as improvement in socioeconomic conditions has also been shown to promote the control of ARF. ${ }^{[15]}$ Improvement of economic circumstances in disadvantaged communities is therefore also an important component of the management of ARF/RHD. Until such communities are economically empowered, ARF/RHD will continue to be a problem despite interventions to control the disease. All these interventions may prove to be a challenge in some parts of SA and in countries in the rest of Africa. 


\section{A M Cilliers}

Paediatric Cardiology Unit, Chris Hani Baragwanath Academic

Hospital, Johannesburg, South Africa, and Faculty of Health Sciences, University of the Witwatersand, Johannesburg

\section{Corresponding author: A M Cilliers (antoinette.cilliers@wits.ac.za)}

1. Carapetis JR, Steer AC, Mulholland EK, Weber M. The global burden of group A streptococcal diseases. Lancet Infect Dis 2005;5(11):685-694. [http://dx.doi.org/10.1016/S1473-3099(05)70267-X] 2. Mayosi B, Robertson K, Volmink J, et al. The Drakensberg declaration on the control of rheumatic fever and rheumatic heart disease in Africa. S Afr Med J 2006;96(3):246.

3. Carapetis JR, Zuhlke LJ. Global research priorities in rheumatic fever and rheumatic heart disease. Ann Pediatr Cardiol 2011;4(1):4-12. [http://dx.doi:10.4103/0974-2069.79616]

4. Tibazarwa KB, Volmink JA, Mayosi BM. Incidence of acute rheumatic fever in the world: A systematic review of population-based studies. Heart 2008;94(12):1534-1540. [http://dx.doi:10.1136/ hrt.2007.141309]

5. McLaren MJ, Hawkins DM, Koornof HJ, et al. Epidemiology of rheumatic heart disease in black school children of Soweto, Johannesburg. BMJ 1975;3(5981):474-478

6. Sliwa $\mathrm{K}$, Carrington M, Mayosi BM, et al. Incidence and characteristics of newly diagnosed rheumatic heart disease in urban African adults: Insights from the Heart of Soweto study. Eur Heart I 2010;31(6):719-727. [http://dx.doi:10.1093/eurheart/eurheart/ehp530]
7. Marijon E, Ou P, Celermajer DS, et al. Prevalence of rheumatic heart disease detected by echocardiographic screening. N Engl J Med 2007;357(5):470-476. [http://dx.doi.org/10.1056/NEJMoa065085]

8. Beaton A, Okello E, Lwabi $\mathrm{P}$, et al. Echocardiography screening for rheumatic heart disease in Ugandan schoolchildren. Circulation 2012;125(25):3127-3132. [http://dx.doi.org/10.1161/ CIRCULATIONAHA.112.092312]

9. Jingi AM, Noubiap JJ, Kamden P, et al. The spectrum of cardiac disease in the West Region of Cameroon: A hospital-based cross-sectional study. Int Arch Med 2013;6(1):44. [http://dx.doi org $/ 10.1186 / 1755-7682-6-44$

10. Kennedy N, Miller P. The spectrum of paediatric cardiac disease presenting to an outpatient clinic in Malawi. BMC Res Notes 2013;6:53 [http:dx.doi.org/10.1186/1756-0500-6-53]

11. Cilliers AM. Rheumatic fever and rheumatic heart disease in Gauteng on the decline: Experience at Chris Hani Baragwanath Academic Hospital, Johannesburg, South Africa. S Afr Med 2014;104(9):632-634. [http://dx.doi:10.7196/SAMJ.8318]

12. Sutton C. Ascertainment of rheumatic heart disease in children in the Limpopo Province of South Africa C. Astracts of Proceedings of the 15th Annual SA Heart Congress, Durban 2014. SA Heart, Journal of the South African Heart Association 2014;11(4):204.

13. Arguiedas A, Mohs E. Prevention of rheumatic fever in Costa Rica. J Pediatr 1992;121(4):569-572. [http://dx.doi.org/10.1016/S0022-3476(05)81146-1]

14. Nordet P, Lopez R, Duenas A, Sarmiento L. Prevention and control of rheumatic fever and rheumatic Nordet P, Lopez R, Duenas A, Sarmiento L. Prevention and control of rheumatic fever and rhe
heart disease: The Cuban experience (1986-1996-2002). Cardiovasc J Afr 2008;19(3):135-140.

15. DiSciascio G, Taranta A. Rheumatic fever in children. Am Heart J 1980;99(5);635-658. [http://dx.doi. org/10.1016/0002-8703(80)90739-5]

S Afr Med J 2015;105(5):361-362. DOI:10.7196/SAMJ.9433 